\title{
BMJ Open Investigating the benefits and challenges of including bereaved women in research: a multifaceted perinatal audit in a socially disadvantaged French district
}

\author{
Priscille Sauvegrain (D) ,,2 Jennifer Zeitlin ${ }^{1}$
}

To cite: Sauvegrain P, Zeitlin J. Investigating the benefits and challenges of including bereaved women in research: a multifaceted perinatal audit in a socially disadvantaged French district. BMJ Open 2020;10:e034715. doi:10.1136/ bmjopen-2019-034715

- Prepublication history for this paper is available online. To view these files, please visit the journal online (http://dx.doi org/10.1136/bmjopen-2019034715).

Received 07 October 2019 Revised 25 April 2020 Accepted 10 June 2020

Check for updates

(C) Author(s) (or their employer(s)) 2020. Re-use permitted under CC BY-NC. No commercial re-use. See rights and permissions. Published by BMJ.

${ }^{1}$ Université de Paris, CRESSEPOPé, INSERM, INRA, Paris, France

${ }^{2}$ Maternity Unit, GH Pitié-

Salpêtrière, AP-HP, Paris, France

Correspondence to

Priscille Sauvegrain

priscille.sauvegrain@inserm.fr

\section{ABSTRACT}

Objectives To describe experiences including interviews with bereaved women in a clinical audit.

Design The data come from an audit of all stillbirths and neonatal deaths at $\geq 22$ weeks of gestation in SeineSaint-Denis, a disadvantaged French district in 2014. We included bereaved women using a questionnaire that also contained open-ended questions administered in an interview format by a midwife-investigator several weeks after the death. The study included a referral protocol for bereaved women with unmet needs revealed during the interviews. A psychological support for the three midwifeinvestigators was set-up, in the form of a support group. Setting The 11 maternity hospitals in the district. Participants 218 women (227 deaths).

Analyses Data come from medical records, maternal interviews, the reviews of the audit's expert panel and written narratives of their experiences provided by the midwife-investigators. Quantitative data were analysed statistically, and qualitative data thematically.

Results One-third (75) of the women agreed to an interview, but acceptance ranged from $6 \%$ to $60 \%$ by maternity unit. Characteristics of respondents and nonrespondents were similar. Members of the audit's expert panel reported that $41 \%$ of the interviews contained new information relevant to their assessment. Of the women interviewed, 35\% were referred to a medical professional, psychologist or social worker. Midwife-investigators' experiences illustrated the benefits of a support group with three main themes identified: improving their interactions with bereaved women as well as medical teams and protecting their psychological well-being.

Conclusion These results showed that including interviews with bereaved women in audit designs was feasible and provided valuable information on women's care and social circumstances that were not available in medical records. They also highlight the importance of implementing referral protocols for the bereaved women, used in over one-third of cases, as well as providing support for study investigators.

\section{INTRODUCTION}

The importance of user groups and patient associations in research and policy-making
Strengths and limitations of this study

- A multifaceted audit to investigate high rates of perinatal mortality in a socially disadvantaged district included data abstraction from medical records, interviews with bereaved women and peer-reviews by an expert panel.

- A referral protocol was put into place for bereaved women identified as having unmet needs identified by the midwife-investigators.

- A support group for the three midwife-investigators was established and they contributed written narratives of their experiences 6 months after the study's end.

- Women who refused an interview did not differ from women who accepted, but there was wide variation in acceptance rates by maternity unit.

- This study sheds light on the benefits and the difficulties of interviewing bereaved women for perinatal audits and stresses the need for designing studies with support for women and investigators.

related to the provision and quality of healthcare is growing. ${ }^{1}$ Nonetheless, in perinatal audits, the inclusion of patients and families is rare and the limited experiences reported in the literature are recent. ${ }^{2-5}$ Including bereaved women in perinatal death audits could make it possible to obtain more complete information, especially about their antenatal care and socioeconomic circumstances. However, recruiting women who have just lost a child into a research protocol requires careful thought because of their vulnerability after this experience.

In the disadvantaged French district of Seine-Saint-Denis, an audit was commissioned by the regional health agency in 2013 because of high rates of infant and perinatal mortality. At that time, infant mortality was 4.4 per 1000 live births compared with 3.2 in France. ${ }^{6}$ A Delphi consultation with district 
clinicians and parents' organisation to sound out their views on causes of the high mortality rates before the audit's onset highlighted difficulties linked to access to care and social disadvantage. ${ }^{78}$ Because this information is not always available in medical records, interviews with bereaved women were integrated into the study design.

The interviews were conducted by three experienced midwife-investigators. A protocol was developed with the district perinatal health network to refer women with unmet needs identified during the interview. In addition, a support group run by a clinical psychologist was set up for the midwife-investigators. The aim was to support them for their frequent contact with bereaved women and their families as well as with hospital staff. The purpose of this article is to describe and discuss (1) the contribution of interviews with bereaved women to the audit's research aims, (2) the benefits for the women themselves, especially related to use of the referral protocol and (3) the midwife-investigators' experiences with the support group.

\section{MATERIAL AND METHODS Study design}

The audit included all stillbirths and neonatal deaths (up to the 28th day of life) at or after 22 weeks of gestation in the 11 maternity units of the Seine-Saint-Denis district of births occurring in in from 1 January to 31 December 2014. All cases were included unless the family explicitly refused. The research team did not directly approach potential participants, rather the medical team acted as a liaison between the women and the research team. During the maternity hospitalisation or after the death in the neonatal unit, the medical team provided information about the study and asked women if they agreed to be contacted for an interview. Women's care did not vary as a result of their decision to participate. Women who agreed were contacted by one of the three midwife-investigators 4-6 weeks later to arrange an interview in the location of their choice. Professional interpreters with previous experience in qualitative research were available, if necessary.

The midwife-investigators were recruited by advertising the positions on an employment website for epidemiological research and through the French midwives' professional society. In interviews with potential candidates, we sought to confirm sufficient clinical experience and maturity to manage complex medical or psychosocial situations that could arise during the maternal interviews or in interactions with medical staff. Personal considerations were also discussed, including the candidates' own experiences with perinatal death. The three midwife investigators who were recruited for the study had at least 15 years working in maternity care and none had personal experience with perinatal bereavement. Their role was to collect socioeconomic and medical data from medical records and the results of follow-up tests. They used a standard protocol which did not include any identifying information (random codes were assigned for each woman at inclusion by the midwife coordinator). They also conducted interviews with the women.

After further anonymisation (removal of the hospital code), each case was assessed by at least one expert from a panel comprising 14 senior clinicians (obstetricians, neonatologists and midwives). The purpose was to identify suboptimal factors and to determine whether the death might have been prevented by their modification. More details on the audit's methodology audit have been published elsewhere. ${ }^{9}$

\section{Questionnaire for bereaved women}

A multidisciplinary group with experience in bereavement care (sociologist-midwife (PS), sociologist, psychologist) developed the questionnaire in order to minimise any negative impact on the women of being interviewed about the death of their baby. The goals of this questionnaire (available on request), designed to take about 40 min, was to provide information not systematically available in the medical records about demographic and social characteristics, living conditions and care during the pregnancy. The questionnaire included questions about women's understanding of the medical follow-up and their evaluation of staff support during delivery. The questionnaire was study-specific and did not include preexisting psychometric scales. Extra time at the end of the interview allowed women to express other concerns. The midwives also noted information about the conditions of each interview: the location, presence of an interpreter, the woman's apparent understanding of the questions, her attitude towards the interview and use of the referral protocol.

The midwife-investigators received a half-day training in qualitative methods covering the different steps for conducting and analysing interviews and the importance of verbatim transcription of answers to the open-ended questions. During the interviews, the midwife-investigators made notes about the women's responses and then transcribed them at the end of the interview. We chose not to record the interviews for fear that it would increase the refusal rate, and the women did not receive a copy of the transcripts.

When the midwives encountered situations in which they considered that the woman required medical or other services, they referred in accordance with the referral protocol. This protocol was developed together with hospital teams and parents' associations in the district and identified the professionals to whom women should be referred for different types of care or services according to their place of residence.

\section{Midwife-investigators' descriptions of their experience of the support group}

A half-day support group led by a clinical psychologist who was also a midwife was set up every 2 months to enable the investigators to consolidate their knowledge of perinatal bereavement care, have a space in which to share their experiences and be supported as appropriate. 
They could also schedule telephone consultations with the psychologist if needed. Six months after the end of the study, each midwife-investigator was asked to provide a written document describing her experiences during the study and in the support group. The aim of this document was to provide feedback to the coordination team about this component of the study protocol; there was no predefined format for this document.

\section{Analysis}

Data from the medical records, responses to closed questions from the maternal interviews and information about suboptimal factors from the external assessments were entered into a database and analysed quantitatively. For comparisons of categorical variables, we used $\chi^{2}$ tests or Fisher's exact tests when cell sizes were below 5 ; means were compared with t tests. Free-text responses from the maternal interview and the midwives' written descriptions were extracted by one investigator (PS) using N'Vivo 10 (QSRInternational) for the analyses. We identified comments that were related to women's experiences of care which were used to illustrate how the interviews contribute to understanding the care process and its failures. The writings of the midwives were analysed thematically, according to the method of grounded theory. ${ }^{10}$ First, we coded the texts line by line with N'vivo 10, using an inductive approach (PS), followed by thematic grouping (PS). ${ }^{11}$ These analyses were then shared with JZ, in order to obtain an agreement on the themes. Dissentions did not occur in the coding of this corpus. Finally, we consulted with the midwife-investigators as well as the psychologist who had led the group, who reviewed the results; they had no further information to add.

\section{Patient and public involvement}

Two parents' organisations (Petite Emilie and SOS Prémas, see acknowledgements) were involved in the Delphi process prior to the audit and in the elaboration of the referral protocol.

\section{RESULTS}

\section{Maternal interviews}

Description of the women who agreed to be interviewed

Over the study period, there were 172 stillbirths and 77 neonatal deaths among 25037 births that took place in the district maternity units. Because 22 families refused to participate in the audit, the study included 218 women with 227 infants (due to nine twin pregnancies in which both children died). Of them, 101 agreed to be contacted for an interview. However, there were 19 secondary refusals, and seven more could not be reached. Interviews were therefore conducted with 75 women ( $34 \%$ of all women included in the audit).

Inclusion rates by hospital ranged from $6 \%$ to $60 \%$. Two centres had an inclusion rate below $15 \%$, four between $20 \%$ and $<40 \%$, four between $40 \%$ and $50 \%$ and one included $60 \%$ of women. The 75 women were similar in age, parity, country of birth and nationality to those who refused, but were less likely to have no health insurance coverage $(3.0 \%$ vs $10.3 \%)$, as shown in table 1 . Obstetric history, preexisting medical risk factors and pregnancy outcomes were also similar between women who were and were not interviewed.

\section{Conducting the interviews and use of the referral protocol}

The interviews lasted an average of $90 \mathrm{~min}$ (range 40 minutes- 4 hours) and were conducted between March 2014 and March 2015. Most women chose the option of meeting at home, although 11 interviews took place in a healthcare setting and two women chose a public park (table 2). Professional interpreters were used for five interviews. Most women responded to the questionnaire without difficulty, but questions had to be reformulated or explained for some women who did not need translators but who did not speak French fluently. At the end of the interview, $85 \%$ of the women reported that they were satisfied and pleased to have shared their experience or to have participated in this research: 'It's gratifying to have someone come to us; it shows that there is someone who is asking questions' (Interview 14). Eleven women were more neutral, and one was unhappy because of a misunderstanding; she had expected to get further information about her child's autopsy.

The referral protocol was used for $35 \%$ of women. As shown in table 2, most referrals were to the district's parental bereavement services, followed by maternal and child health services, parental organisations and the maternity unit.

\section{Information provided by the maternal interviews}

The interviews made it possible to complete information in the medical files about care during pregnancy and in particular difficulties accessing care. Of the women interviewed, 22\% described difficulties making appointments and $24 \%$ getting to them, because of lack of child care, work responsibilities and financial constraints. Fifteen percent of women reported going without care for financial reasons.

These difficulties impacted on women's care pathways: 'I had been told in the previous pregnancy that because of the problem of the detached placenta, as I had a cesarean and my baby had been hospitalized for 3 weeks, that for a future pregnancy I had to be followed at the hospital. I was also told about the need to take [aspirin. But when I called the maternity unit to make an appointment, I was told it could be done only from the $6^{\text {th }}$ month' (Interview 27). Later in the interview, she regretted that her general practitioner had not insisted that the hospital agree to provide her prenatal care earlier. For women requiring specialised care, the time and financial burdens could be high: 'For the specialized ultrasound examinations, it took me about 3 hours to get there and back. And appointments were frequent. They are very expensive in addition, I spent almost $€ 600$. Fortunately, my 
Table 1 Comparison of social and demographic characteristics of women who were and were not interviewed

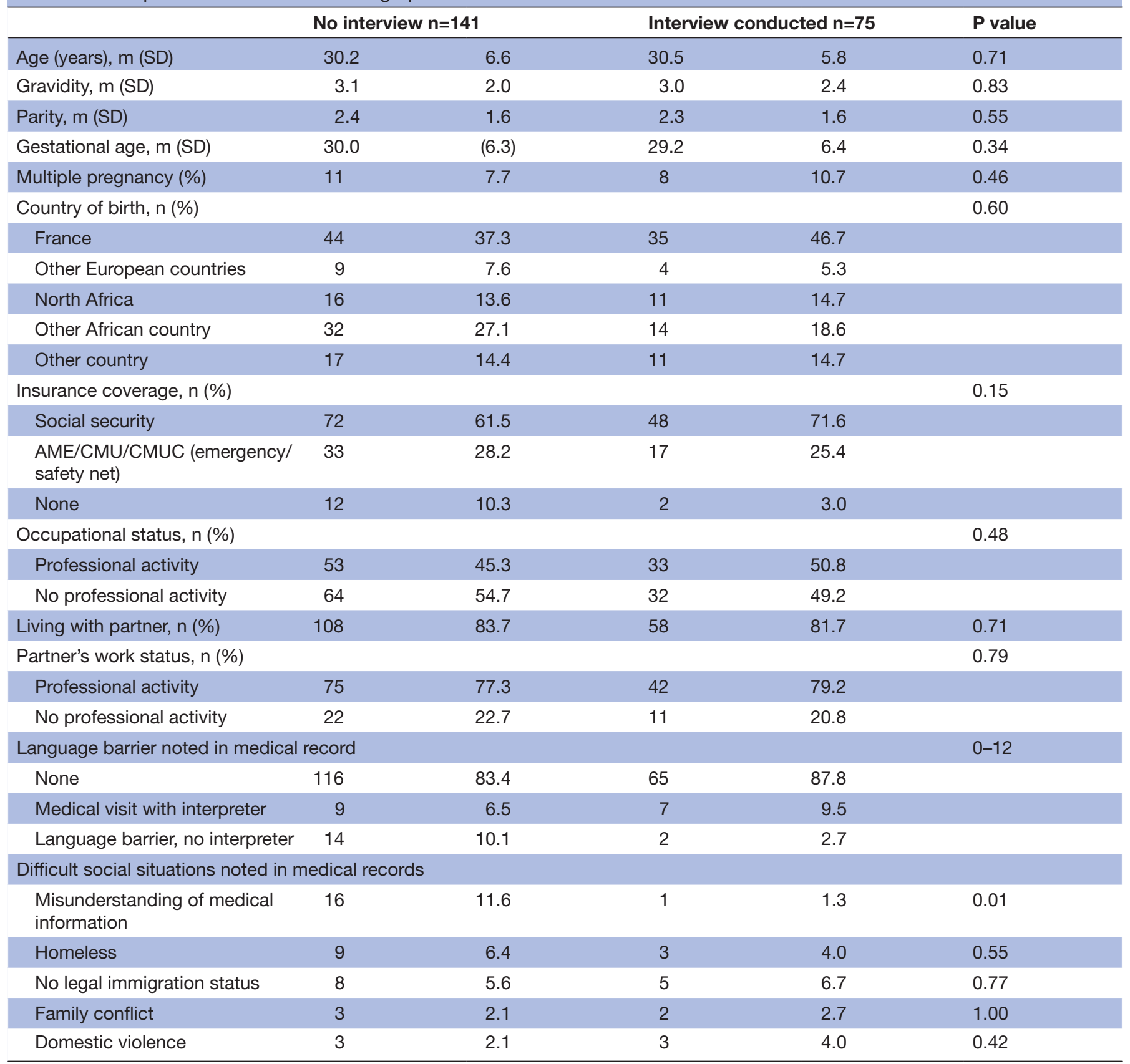

(supplemental private) insurance company reimbursed a part of the costs' (Interview 45).

Once they entered the healthcare system, however, most of the women reported very good (56\%) or good $(25.3 \%)$ treatment by professionals, emphasising the kindness of the medical and paramedical staff. Nonetheless, $10.7 \%$ of women were not at all satisfied. Their comments illustrated a gap between the care expected and received. 'Then I had my appointment with the doctor at the prenatal diagnosis center. She did not examine me because, she said, 'You've been to the emergency room too many times, I don't want to be intrusive'. The relationship went wrong. I was expecting someone to tell me what to do on a daily basis: to move, not to move, to be on strict rest... because I had heard so many different opinions. The tone and manner in which she spoke was neither right nor reassuring' (Interview 15).

\section{Usefulness of the interviews for expert review of cases}

A panel of medical experts reviewed suboptimal factors and potentially preventable deaths. The experts were given access to the transcripts of the maternal interviews, when available. As part of the assessment, they were asked whether the interviews had allowed them to identify additional suboptimal factors (Yes, No) and contributed to their assessments (Yes, No. Please explain). In 32 (41\%) of the 78 deaths ( 75 women, including three twin pregnancies) with maternal interviews, the experts responded 
Table 2 Conduct of the interviews

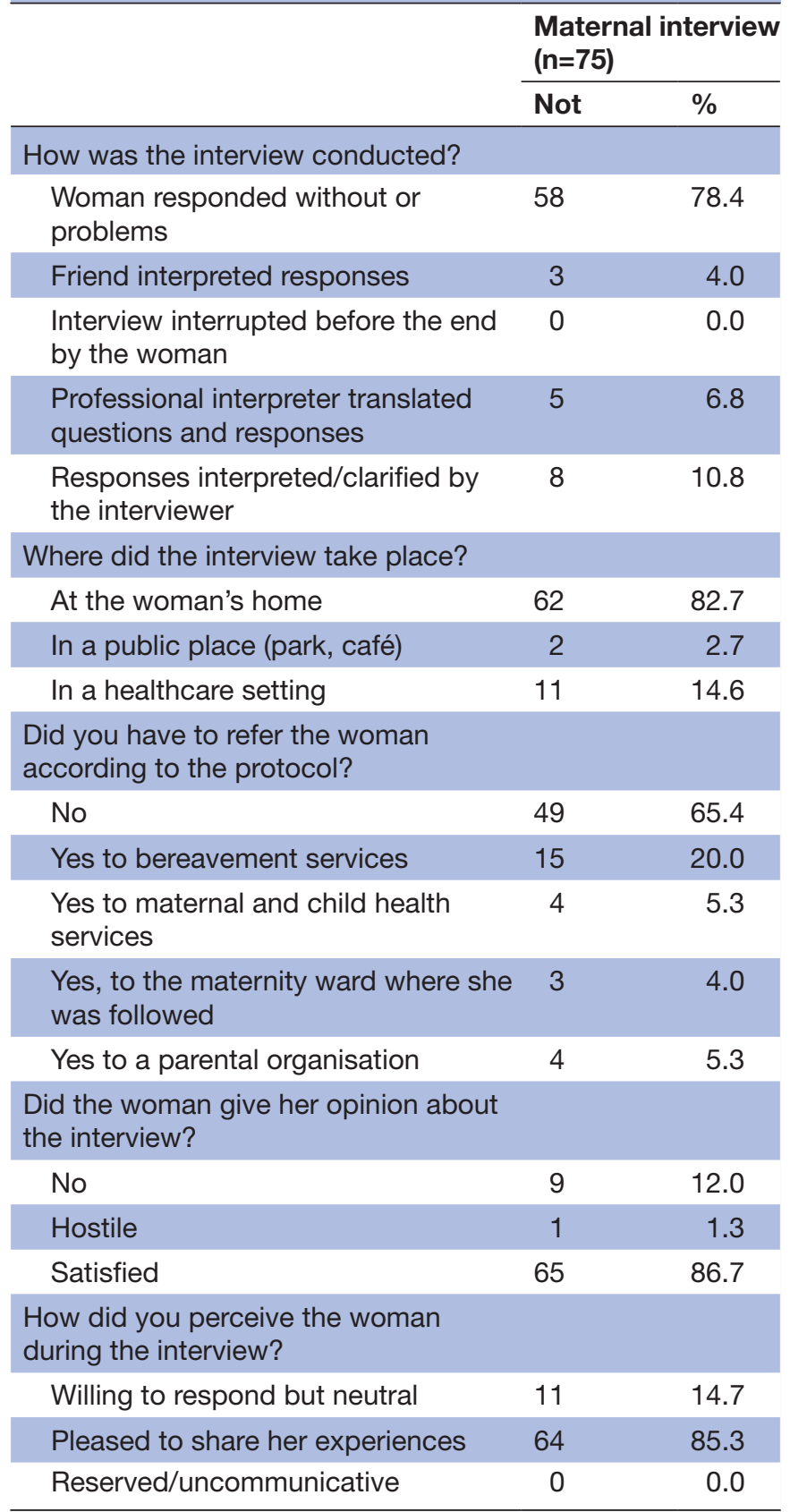

yes to this question. Reasons provided included a better understanding of the woman's living conditions and social circumstances: 'No family support may have contributed to the absence of pregnancy follow-up' (Expert file/ interview 22) or to the woman's isolation: 'The interview with the woman highlighted her psychological distress and loneliness (spouse studying abroad), which did not appear in medical observations because it was not spotted' (Expert file/interview 24). In some cases, the questionnaires provided medical information that was not included in the file: 'The interview makes it possible to know that her blood pressure was elevated at the last visit' (Expert file/interview 20).
The experts in their reports also pointed to problems in care coordination between different practitioners or different facilities, for example: 'The information in the interview demonstrates step by step the major lack of coordination of care for this patient: Due to her complicated diabetes, pregnancy might have been contraindicated in her case. A preconceptional consultation should have been very strongly considered, with optimization of her glycemic control if she chose to become pregnant. The patient should probably have been managed from the start by a multidisciplinary team of specialists at a high level maternity unit with an adult ICU, given her risks. The follow-up here started gradually with the usual gynecologist and no clear consultation with diabetologists or nephrologists. The patient's providers were her general practitioner and a private practice nurse, which shows the low level of medical supervision she received' (Expert file/Interview 73).

The perceived value of having the woman's perspectives is underscored by an expert's comment in one case without an interview: 'It seems to me that the interview could have provided significant additional information, concerning in particular the monitoring of this pregnancy'.

\section{The midwife-investigators' support group, led by a psychologist}

The support group was an important part of the three midwife-investigators' decision to participate in the study. 'This proposal tempted me from the beginning because it converges with a question that is essential to me, both personally and professionally: how to support people dealing with death in a society that hides it?' (Midwife 1). The analysis of their experiences, described 6 months after the study, revealed three themes about the benefits of the group related to the emotional weight of their encounters with bereaved women, interactions with the healthcare teams and personal well-being.

The first theme was the need to discuss their experiences managing the grief expressed by the women during the interviews. Although perinatal mourning is inherent to the practice of midwifery, death is uncommon in a conventional practice: 'For us, even more than for providers who treat sick people, death is a failure, even if we are regularly confronted with life-threatening events such as potential preterm birth or miscarriages... Some interviews were very hard. Even if you feel armed against the pain of the patients, their story, the duration of these stories, the emotional burden that goes with them, are hard to handle' (Midwife 2). 'Another very positive aspect of these sessions was being able to hear the others [midwife-investigators] talk about their difficulties. At these moments, we became aware of how hard what we were doing really is and the fact that we must not minimize the weight it might have' (Midwife 3).

A second theme centred on experiences interacting with medical teams. The study's protocol required the midwives to obtain medical records and other documents 
from these teams, whose members did not necessarily want to remember or think about the perinatal death which they experienced as a failure. 'It is enough to meet a maternity team facing such an event to confront our own feelings of failure and our personal suffering in the face of death' (Midwife 3). Completing the files led the midwives to analyse the cases from a retrospective point of view and they could note the dysfunction and failures of the health system: 'One of the major difficulties for me was containing my emotions in the face of what I could identify as practice mistakes. What do you do when you find information that, for you, is synonymous with a lifethreatening situation and was not interpreted as such, leading ultimately to the death of a fetus?' (Midwife 1).

Finally, a third theme was their personal appreciation of the value of the exchanges within the group. By giving them support in difficult situations, they reported feeling that their importance and worth was being recognised: 'This time for reflection seemed to me to be very respectful of us as professionals... The fact that we could think of ourselves and the consequences of what we were going to experience was very gratifying and empowering' (Midwife 1 ). Being able to express and share the difficulties of the project during the group support sessions enabled the midwives to accept and make sense of them: 'The sessions allowed me to express anger at what I could identify as a failure, violating either the principle of neutrality or the necessary confidentiality [...] It allowed me to distance myself and to hold on over time, but also gave me time for introspection' (Midwife 3).

Only one of the three midwives used an individual phone session with the psychologist. But all three stated that it had reassured them to know that they could use this type of support between the group sessions.

\section{DISCUSSION}

As part of an audit of perinatal deaths that took place in 2014 in a disadvantaged district in the Parisian region, the research team sought to include the bereaved mothers at the data collection stage. Seventy-five questionnaires in an interview format were conducted with women with characteristics similar to all women in the district who lost a child to stillbirth or neonatal death. These interviews provided important information about the women's prenatal care and were valuable to the experts assessing the cases. Our analysis of this experience revealed the importance of support protocols for both the bereaved mothers and the investigators. More than a third of the women were found to be in need of health or social services, according to the referral protocol. The experience of the midwifeinvestigators participating in the support group that met every 2 months illustrates the challenges for research teams supporting perinatal bereavement, medical teams in distress and their own emotional experiences.

The strengths of this study are its populationbased design and its socioeconomic context, focused on disadvantaged women who are at higher risk of perinatal death, but are less likely to participate in research studies. ${ }^{12}$ Although there have been a few initiatives to include bereaved women in studies of perinatal death, ${ }^{413}$ this approach is still very uncommon. ${ }^{214}{ }^{15}$ It is thus important to illustrate its benefits and challenges in different contexts in order to develop this research further. A further strength of this study is its parallel focus on the midwife-investigators; although support groups for hospital staff have been reported, ${ }^{16}{ }^{17}$ this is an original approach for a research team. ${ }^{18}$ Our analyses were based on the midwives' written assessments 6 months after the study was over, giving them time to gain perspective on their experiences; however, other designs, such as keeping a journal during the study, might have captured other, more immediate, reactions.

Among the study limitations, we did not have information on why women refused an interview. Differences in the inclusion rates by hospital, alongside similar maternal characteristics among responders and non-responders, suggests that the medical teams' approach to presenting the study played a role. ${ }^{19}$ However, only one-third of women were interviewed and we cannot exclude the existence of other biases. Although one concern was that the interviews would cause women to relive the experience of their child's recent death, study design features were developed to minimise these risks including holding the interview after several weeks, having experienced midwifeinvestigators and designing the questionnaire with multidisciplinary specialists. One of the reasons for conducting research on study designs that include bereaved women is precisely to provide evidence of their importance and feasibility for medical personnel who are hesitant about upsetting or placing an additional burden on women soon after they have experienced a stillbirth or neonatal death. Our results showing that interviews improved the quality of the audit, were useful for helping women still struggling to deal with their loss, and were well accepted by women are reassuring in this regard. Further studies on women's reasons for refusal as well as their experiences participating in research could help improve protocols; these could include more participatory designs, such as getting input from women on the transcripts of their interviews. Finally, having research from different countries is important for assessing the external validity of these findings.

Audits are a key tool for surveillance and evaluation of in utero and infant deaths as shown by those conducted routinely in the UK, ${ }^{20}$ Australia and New Zealand ${ }^{21}$ and the Netherlands, ${ }^{22}$ but bereaved mothers do not participate in providing information for these audit procedures. Audits have not been widely used in France, although there are a few regional examples ${ }^{23-26}$ which have not included bereaved parents. Our study showed that speaking to women provided important information on their social circumstances, obstetric history and difficulties in access to care that were not available in medical records and that affected assessments of the appropriateness of care. This constitutes a strong rationale for 
including interviews with mothers in perinatal audits to ensure that preventable health system factors are identified. An English study is testing an innovative method of including bereaved parents in clinical mortality reviews in two hospitals ${ }^{4}$ and this could also be a way to ensure that information on the woman's circumstances and care experiences are readily available in the files for external audit.

Our study shows that it is possible to interview mothers after a perinatal death, including women in disadvantaged areas and who are not fluent in national languages. The provisions to adapt to women's needs in the protocol, such as allowing for interviews in places other than the woman's home and having professional interpreters who could accompany the study midwives, were necessary for including some women and used in one out of five interviews. These interviews 4-6 weeks after the death also showed insufficient support after discharge, as found elsewhere. ${ }^{13}$ Despite the presence of a specialised service for perinatal bereavement care in the district, ${ }^{27}$ not all of the maternity units referred women for these services. High use of the study's referral protocol underscored the importance of having experienced midwives conduct interviews in order to identify and appropriately refer women with health or other needs. ${ }^{28}$

The difficult experience of professionals dealing simultaneously with their response to perinatal death and with mourning parents is recognised as particularly acute. ${ }^{29} 30$ As a recent literature review shows better training and support is essential ${ }^{31}$ for teams facing perinatal loss. ${ }^{32}$ Small groups and the opportunity to contact a psychologist individually appear to enhance support for research teams substantially. This issue has been raised in the literature for teams conducting research with qualitative methods ${ }^{33} 34$ but not for those conducting clinical audits. The write-ups by the three midwife-investigators showed the extent to which daily contact with bereaved women and witnessing shortcomings in care could bring up strong feelings related to their professional ethics and personal beliefs. The psychotherapist and the group provided a contained space for sharing these experiences. This approach would be valuable for investigators or medical teams working on audits in other areas, for example, maternal mortality or childhood cancer, who face similar challenges.

\section{CONCLUSION}

We found that interviewing bereaved women as part of a perinatal audit is feasible, provides valuable information and can have benefits for the women themselves. Women's experiences navigating the healthcare system or with difficult social circumstances are important for accurately identifying suboptimal care and designing quality improvement and prevention campaigns. Interviewing bereaved women also provides information about postdischarge care. However, our study shows that research including bereaved parents requires specific design features. It was imperative to have adequate arrangements for referral to healthcare providers and parental associations which requires having investigators who are experienced healthcare professionals. Another key feature was providing support to the study investigators for their daily contact with maternal grieving and the distress of healthcare professionals. Setting up a psychologist-led support group made the investigators feel recognised and respected, and improved their ability to provide support to the women. In conclusion, our results provide a strong justification for including interviews with bereaved women in perinatal audits, but only if sufficient attention is given to the needs of bereaved women and investigators.

Acknowledgements We would like to thank the personnel in the maternity and neonatal units in Seine-Saint-Denis and, most particularly the study contact points and department heads, who were deeply involved in this study. We express our gratitude to the women and families who agreed to an interview and who met with us. We also acknowledge the other members of our research team, especially Micheline Garel, psychologist, the three research midwives, Myriam Bonnin, Anne-Isabelle Tumelin and Barbara Révillon, and two anthropologists, Raquel Rico-Berrocal and Erwan Le Meneur.We also thank the panel of experts and the members of the external scientific committee. We would like to thank all the participants in the Delphi and especially the parents' associations Petite Emilie and SOS Prémas. One is a specialist in accompanying the perinatal bereavement of parents (http://petiteemilie.org/). The other focuses on prematurity, and thus also on perinatal deaths when they occur (https://www.sosprema.com/page/173781accueil). Finally, the interviews could not have been held without our collaboration with the PMI (Protection Maternelle et Infantile) center 'Empathie 93', specialised in the support of perinatal mourning in the district. We thank its members especially.

Contributors PS and JZ conceived the study, performed the analyses and wrote the manuscript.

Funding This work was supported by the Regional Health Agency of lle-de-France.

Patient consent for publication Not required.

Ethics approval This study obtained the authorisation of the Advisory Committee on health research information on 29 0ctober 2013. The collection of the medical data and the constitution of databases were authorised by the CNIL on 8 January 2014, which was followed by an amendment on the modalities for obtaining consent. The Ethics Committee of Inserm/IRB00003888 issued a favourable opinion n 13-39 for the study as a whole and more particularly for the maternal interviews on 11 December 2013. This study was approved by the French Advisory Committee on Health Data in Medical Research and the French National Commission for Data Protection and Liberties.

Provenance and peer review Not commissioned; externally peer reviewed.

Data availability statement Data are available upon reasonable request. Ethical restrictions regarding participant privacy prohibit the authors from making the entire data set publicly available. The corresponding author Priscille Sauvegrain ( priscille.sauvegrain@inserm.fr) may be contacted in order to request the data.

Open access This is an open access article distributed in accordance with the Creative Commons Attribution Non Commercial (CC BY-NC 4.0) license, which permits others to distribute, remix, adapt, build upon this work non-commercially, and license their derivative works on different terms, provided the original work is properly cited, appropriate credit is given, any changes made indicated, and the use is non-commercial. See: http://creativecommons.org/licenses/by-nc/4.0/.

ORCID iD

Priscille Sauvegrain http://orcid.org/0000-0003-1014-6655

\section{REFERENCES}

1 Armstrong N, Herbert G, Aveling E-L, et al. Optimizing patient involvement in quality improvement. Health Expect 2013;16:e36-47.

2 Cronin RS, Bradford BF, Culling V, et al. Stillbirth research: recruitment barriers and participant feedback. Women Birth 2020;33:153-60. 
3 Bakhbakhi D, Siassakos D, Burden C, et al. Learning from deaths: parents' active role and engagement in the review of their Stillbirth/ perinatal death (the parents 1 study). BMC Pregnancy Childbirth 2017;17:333.

4 Bakhbakhi D, Siassakos D, Storey C, et al. Parents 2 study protocol: pilot of parents' active role and engagement in the review of their Stillbirth/perinatal death. BMJ Open 2018;8:e020164.

5 Redshaw M, Henderson J. Care associated with stillbirth for the most disadvantaged women: a multi-method study of care in England. Birth 2018;45:275-85.

6 Sauvegrain P, Carayol M, Piedvache A, et al. Low autopsy acceptance after stillbirth in a disadvantaged French district: a mixed methods study. BMC Pregnancy Childbirth 2019;19:117.

7 Sauvegrain P, Carayol M, Ego A, et al. How can we understand the high risk of infant and perinatal mortality in a geographical area? the example of the situation in Seine-Saint-Denis. J Bull Epidémiol Hebd2015;6:116-22.

8 Sauvegrain P, Rico-Berrocal R, Zeitlin J. [Why is perinatal and infant mortality high in the Seine-Saint-Denis district? A consultation with healthcare providers using a Delphi process]. J Gynecol Obstet Biol Reprod 2016;45:908-17.

9 Sauvegrain P, Carayol M, Piedvache A, et al. Understanding high rates of stillbirth and neonatal death in a disadvantaged, highmigrant district in France: a perinatal audit. Acta Obstet Gynecol Scand 2020. doi:10.1111/aogs. 13838

10 Strauss A, Corbin J. Grounded theory in practice: procedures, canons and evaluative criteria. Qualitative Sociology 1990;13:3-21.

11 Hsieh H-F, Shannon SE. Three approaches to qualitative content analysis. Qual Health Res 2005;15:1277-88.

12 Tourangeau R, Edwards B, Johnson TP, et al. Hard-to-survey populations. Cambridge University Press, 2014.

13 Siassakos D, Jackson S, Gleeson K, et al. All bereaved parents are entitled to good care after stillbirth: a mixed-methods multicentre study (insight). BJOG 2018;125:160-70.

14 Breeze ACG, Statham H, Hackett GA, et al. Attitudes to perinatal postmortem: parental views about research participation. $J$ Med Ethics 2011;37:364-7.

15 Redshaw M, Henderson J. Mothers' experience of maternity and neonatal care when babies die: a quantitative study. PLoS One 2018;13:e0208134.

16 Blondeau S. Du Groupe et de la parole à I'hôpital. Connexions 2004;82:19-48.

17 Deneux A. Une pratique des groupes de parole de soignants à I'hôpital général. Revue de psychothérapie psychanalytique de groupe 2008;50:123-32.

18 Dickson-Swift V, James EL, Kippen S, et al. Risk to researchers in qualitative research on sensitive topics: issues and strategies. Qual Health Res 2008;18:133-44.

19 McCosker H, Barnard A, Gerber R. Undertaking sensitive research: issues and strategies for meeting the safety needs of all participants. Forum Qual Sozialforschung / Forum: Qual Soc Res 2001;2.
20 Draper E, Gallimore I, Kurinczuk J, et al. MBRRACE-UK perinatal mortality surveillance report. UK perinatal deaths for births from January to December 2016. Leicester: The Infant Mortality and Morbidity Studies, Department of Health Sciences, University of Leicester, 2018.

21 Flenady V, Mahomed K, Ellwood D, et al. Uptake of the perinatal society of Australia and New Zealand perinatal mortality audit guideline. Aust NZJ Obstet Gynaecol 2010;50:138-43.

22 van Diem MT, Timmer A, Bergman KA, et al. The implementation of unit-based perinatal mortality audit in perinatal cooperation units in the Northern region of the Netherlands. BMC Health Serv Res 2012;12:195.

23 Bucourt M, Papiernick E. Périnatalité en Seine-Saint-Denis. Paris: Médecine-Sciences Flammarion, 1998.

24 Dupuis O, Dupont C, Gaucherand P, et al. Is neonatal neurological damage in the delivery room avoidable? experience of 33 levels I and II maternity units of a French perinatal network. Eur J Obstet Gynecol Reprod Biol 2007;134:29-36.

25 Carrabin N, Huissoud C, Dupont C, et al. Impacts des revues de morbidité-mortalité. Expérience Du réseau Aurore de 2005 à 2007. J Gynécol Biol Reprod 2009;38:328-34.

26 Clavel B, Dupont C, Perrotin C, et al. [Intervention of psychological and ethical professionals of human science in obstetrical morbidity and mortality conferences]. J Gynecol Obstet Biol Reprod 2013;42:383-92.

27 Bruniera E, Jourdan A, Laoufir F, et al. Empathie 93. Une expérience originale de travail de Prévention en Seine-Saint-Denis La Prévention prévenante en action. Toulouse: ERES 2012:210-4.

28 Rotten D, Decroix H, Bolot P. Mortalité et deuil périnatals: de l'accident grossesse suivante. Saint-Denis: Maternité-périnatalité, 2012.

29 Nuzum D, Meaney S, O'Donoghue K. The impact of stillbirth on consultant obstetrician gynaecologists: a qualitative study. BJOG 2014;121:1020-8.

30 Garel M, Gosme-Seguret S, Kaminski M, et al. Ethical decisionmaking in prenatal diagnosis and termination of pregnancy: a qualitative survey among physicians and midwives. Prenat Diagn 2002;22:811-7.

31 Martínez-Serrano P, Palmar-Santos AM, Solís-Muñoz M, et al. Midwives' experience of delivery care in late foetal death: a qualitative study. Midwifery 2018;66:127-33.

32 Ellis A, Chebsey C, Storey C, et al. Systematic review to understand and improve care after stillbirth: a review of parents' and healthcare professionals' experiences. BMC Pregnancy Childbirth 2016;16:16.

33 Johnson $\mathrm{N}$. The role of self and emotion within qualitative sensitive research: a reflective account. Enquire 2009;2:191-214.

34 Melville A, Hincks D. Conducting sensitive interviews: a review of reflections. Law and Method 2016:1-25. 